\title{
Contabilidade Rural: Um estudo com Pequenos Produtores Rurais do Sítio Barra no Munícipio de Orós, Ceará-Brasil
}

\author{
Eliza Costa Dias ${ }^{1}$; Marzo Tereshkove Anacleto e Andrade ${ }^{2 ;}$ Antoniel dos Santos Gomes Filho ${ }^{3}$
}

\begin{abstract}
Resumo: O presente estudo teve como objetivo analisar a utilização da contabilidade do pequeno produtor rural do Sítio Barra em Orós, Ceará-Brasil. O mesmo foi desenvolvido no Sitio Barra, município de Orós, e transcorreu no período de agosto a outubro de 2018. Caracterizar-se por ser um estudo de natureza básica, com procedimento exploratório e foi adotado uma abordagem quantitativa. Tiveram como objeto de pesquisa dez produtores rurais. O instrumento de pesquisa usado foi um questionário estruturado e sua tabulação foi efetuada pelo uso do programa Microsolf Excel, versão 2016, onde a análise dos dados procedeu por distribuição de frequência relativa. Através da análise dos resultados, foi possível observar que os agricultores pesquisados não utilizam a contabilidade em nenhuma forma nas suas atividades rurais, entretanto demonstraram o interesse por conhecimentos e esclarecimentos sobre contabilidade e no que essa possa acrescentar na melhoria das atividades dos agricultores.
\end{abstract}

Palavras-chave: Contabilidade Rural. Pequeno Produtor. Agricultura.

\section{Rural Accounting: A Study with Small Rural Producers of the Sítio Barra in the Municipality of Orós in Ceará, Brazil}

\begin{abstract}
The objective of this study was to analyze the accounting utilization of the small rural producers of Sítio Barra in Orós, Ceará-Brazil. The same was developed in Sitio Barra, municipality of Orós, and ran from August to October 2018. It is characterized as a basic study with an exploratory procedure and a quantitative approach was adopted. Ten rural producers were the object of research. The research instrument used was a structured questionnaire and its tabulation was made using the program Microsolf Excel, version 2016, where the analysis of the data proceeded by distribution of relative frequency. Through the analysis of the results, it was possible to observe that the farmers surveyed do not use accounting in any way in their rural activities, nevertheless they demonstrated the interest in knowledge and explanations about accounting and in what this may add to the improvement of farmers' activities.
\end{abstract}

Keywords: Rural Accounting. Small Producer. Agriculture.

\footnotetext{
${ }^{1}$ Graduanda do curso de Ciências Contábeis da Faculdade Vale do Salgado (FVS). E-mail: elizacostadias@ hotmail.com

${ }^{2}$ Mestre em Sistema Agroindustrial na Universidade Federal de Campina Grande (UFCG). Professor do curso Ciências Contábeis da Faculdade Vale do Salgado (FVS).E-mail:marzo2011@ @otmail.com.

${ }^{3}$ Mestre em Educação pela Universidade Federal do Ceará (UFC). Professor da Faculdade Vale do Salgado (FVS). Coordenador do Laboratório Interdisciplinar em Estudos Organizacionais e do Trabalho (LIEOT-FVS). Pesquisador do Laboratório Interdisciplinar em Estudos da Violência no Centro Universitário Dr. Leão Sampaio (LIEV-UNILEÃO). E-mail: antonielsantos@fvs.edu.br
}

164 Id on Line Rev. Mult. Psic. V.13, N. 43, p. 164-174, 2019 - ISSN 1981-1179

Edição eletrônica em http://idonline.emnuvens.com.br/id 


\section{Introdução}

Com o advento da tecnologia progressivamente presente no agronegócio, vem crescendo a utilização de uma administração mais eficaz nas propriedades rurais. A ferramenta capaz de promover essa gestão é a Contabilidade, auxiliando o produtor por meio de relatórios com as informações efetuadas na propriedade. Embora a Contabilidade Rural existir e estar sempre se desenvolvendo, é pouco utilizada pelos pequenos produtores rurais. Para a maioria dos produtores a contabilidade é usada meramente para fins fiscais, e não é utilizada como ferramenta de planejamento. A contabilidade pode e deve ser usada como ferramenta auxiliar na tomada de decisões, trazendo vantagens, econômicas e financeiras.

No agronegócio ainda falta planejamento, através do uso da contabilidade como ferramenta de negócio, pode-se planejar e avaliar como serão os novos rumos da propriedade. Estudar a importância da contabilidade para o setor da agricultura familiar observando as atividades rurais sem uma devida escrituração, evidenciando para os produtores rurais a relevância da utilização da contabilidade no desenvolvimento do negócio, auxiliando a usufruir os seus benefícios, na organização e no planejamento, bem como nas tomadas de decisões da propriedade.

Justifica-se ainda o desinteresse dos produtores rurais a não utilização da contabilidade, desconhecendo assim os benefícios que essa ferramenta pode trazer, no aumento da produção, pois através dos dados contábeis terá a viabilidade de observar a lucratividade ou não do negócio, e a partir desses proporcionar mais segurança na tomada de decisão, conduzindo o negócio de forma mais confiável e planejada. Promovendo um entendimento ao produtor rural, já que esses na maioria desconhecem o uso da ferramenta contábil, no auxílio das atividades rurais, do mesmo modo que propagar a utilização do uso da contabilidade no agronegócio.

Nesse sentido, a contabilidade permite que o produtor tenha controle e consiga avaliar os recursos necessários para a manutenção da atividade, tornando-se ferramenta de apoio, planejamento e controle para a tomada de decisões. Ressaltando que somente a contabilidade não possibilita o desenvolvimento da atividade. A contabilidade será usada como auxilio de controle e planejamento na obtenção de resultados.

O presente estudo teve como objetivo analisar a utilização da contabilidade do pequeno produtor rural do Sítio Barra em Orós, Ceará-Brasil. Foram objetivos específicos: descrever como os produtores rurais aplicam a contabilidade, bem como demonstrar como as contribuições do conhecimento das ferramentas contábeis agregam valor aos negócios rurais, e, apresentar as melhorias das atividades rurais com a utilização da contabilidade. 
Portanto, a união da contabilidade com a atividade rural concebe vantagens, além de complementar as necessidades de planejar, orçar, organizar e orientar a gestão do pequeno produtor, proporcionando assim meios para que os mesmos possam atingir seus objetivos e crescimento.

\section{Referencial Teórico}

\section{Contabilidade Rural e sua Finalidade}

Com o passar dos anos a contabilidade rural se desenvolve e com ela a necessidade da presença nas empresas de atividades rurais e nos setores agropecuários. A contabilidade rural deve ser instrumento adequado para que se possa atuar de forma eficaz no resultado final.

Segundo Calderelli (2003) a Contabilidade Rural é aquela que tem suas normas baseadas na orientação, controle e registro dos atos e fatos ocorridos e praticados por uma empresa cujo objeto de comércio ou indústria seja agricultura ou pecuária.

A contabilidade rural pode ser compreendida como um instrumento apontando informações sobre pontos positivos e negativos e esclarecendo indicativos na tomada de decisão. Crepaldi (2012) diz que a entidade rural pode ser uma pessoa física ou jurídica, que tenha algum patrimônio como fazenda ou sitio, e que nela desenvolva-se atividade de plantação ou criação de animais, com objetivo de obter produtos que venham suprir necessidades humanas. Para Gomes (2002) a contabilidade é um instrumento fundamental para o controle econômico e financeiro da propriedade rural.

Crepaldi (2005) afirma que a contabilidade rural é pouco utilizada por produtores rurais, e é utilizada apenas para fins de imposto de renda. Em tese Crepaldi (2012) ressalta que se a contabilidade fosse utilizada de melhor forma, essa iria fornecer informações mais objetivas e seguras para possíveis tomadas de decisões.

A atividade rural no Brasil é mais utilizada por pessoa física, por ser menos dispendioso em comparação a pessoa jurídica, proporcionando vantagens no setor fiscal, afirma Marion (2012). No entanto Crepaldi chama atenção:

\footnotetext{
O grande problema para utilização efetiva da contabilidade rural está na complexidade e no custo de manutenção de um bom serviço contábil a dificuldade de separar o que é custo de produção do que é gasto pessoal do empresário rural, a inexistência de recibos, notas fiscais, avisos de lançamentos e cópias de cheques ou extratos de contas bancárias pessoais fazem com que não se possa adotar a contabilidade para esse fim (CREPALDI, 2012, p. 47).
} 
Além da tomada de decisões, existem outras finalidades, nas quais podemos destacar: Fazer o comparativo da atividade com outros agricultores; orientar operações pecuárias e agrícolas; fazer a medição do desempenho econômico e financeiro da empresa e de cada atividade produtiva; Controle em transações financeiras (CHAGAS et al. 2014).

Para se obter informações fidedignas, é necessário ter profissionais responsáveis, éticos, compromissados e que faça o registro contábil conforme as legislações específicas, para evitar que o empresário rural tenha qualquer impedimento com fiscalizações.

Crepaldi (2012) afirma que, por menores que as atividades sejam, o uso de técnicas contábeis é necessário, e muitos agricultores acreditam que por serem pequenos, não necessitam dessas técnicas, arquivando os fatos apenas em suas memórias ou de forma informal. Em virtude da utilização da contabilidade atual sendo um instrumento gerencial, é necessário que todo administrador saiba usa essa ferramenta na gestão de suas atividades.

O produtor rural tem se convencido que precisar estar por dentro das informações de seu Contador para identificar as formas de como deve ser conduzido seu negócio. Com esse novo olhar a contabilidade vai possibilitar a obtenção de mais vantagens, bem como um maior controle sobre sua atividade, viabilizando uma melhor interpretação de custos e índices da empresa.

\section{Contabilidade como Ferramenta para Gestão}

O processo de informação torna se necessário no mundo dos negócios de uma forma que o produtor rural precisa conhecer as informações para que possa escolher a melhor alternativa no uso de suas atividades. A contabilidade vem com o objetivo de ser uma ferramenta de gestão, para alavancar resultados a partir de seus dados, e assim o contador tem de oferecer as informações que possam ser utilizadas no planejamento do negócio (BORILLI . et al., 2005).

Nesse sentido Callado (2011), a contabilidade rural é pouco utilizada pelos produtores como ferramenta gerencial, interpretada como uma técnica difícil em sua execução e que seu retorno prático é baixo. As operações de gestão agrária são consideradas sob três aspectos: o técnico, o econômico e o financeiro. O técnico compreende o estudo da perspectiva de determinada cultura vegetal ou criação de gado, no qual refere-se a escolha de sementes, tipos de alimentação de gado, espécies de fertilizantes e sistema de trabalho, etc. Economicamente analisa se as execuções da operações no que tange ao custo e seus resultados, ou seja o custo 
de cada produção e seu retorno que através desses resultados é obtido o lucro O financeiro verifica a possibilidade na captação de recursos financeiros e na sua forma de aplicação, isto é no movimento de entrada e saída de dinheiro, buscando o equilíbrio financeiro do negócio.

Implementar a contabilidade rural, como mecanismo de gestão no agronegócio é uma tarefa difícil para o contador, pois há uma dificuldade de falta de conhecimento da legislação, de gerenciamento e de contabilidade por parte dos produtores rurais. E para tentar essa inserção o contador tem como tarefa uma aproximação maior com esses produtores e organizações ligadas ao setor, estreitando a distância entre ambos, conscientizando o produtor rural da importância da ferramenta contábil na gestão do agronegócio, o sucesso do negócio está ligado diretamente a uma gestão eficiente. Um grande problema de não fazer a utilização de ferramentas contábeis pela atividade rural é a confiança que os produtores têm em suas experiências, acreditando que podem definir o que é bom ou ruim, somente em fatos existentes, ou com suas próprias premissas.

O gestor deve sempre estar atento ás tarefas de planejar, organizar, direcionar e controlar o administrativo, apresentando sempre planos como orçamentos e controles que permitam acompanhar o andamento da atividade, Crepaldi (2005). É importante que o produtor rural tenha a visão que a contabilidade é uma ferramenta necessária para o agronegócio.

\section{A Contabilidade de Custos no Agronegócio}

O sistema de custo irá diferenciar conforme o nível de variedade de atividades compostas, do mesmo modo que a estrutura organizacional e operacional. Normalmente o produtor ver o levantamento dos custos um exercício difícil, mas com a informação cada vez mais obtida de maneira rápida através da tecnologia, no campo a obtenção de dados também ficou mais fácil. Essas informações, são de extrema importância para a análise contábil, é necessário destacar que a tecnologia e a contabilidade também vão gerar custos, entretanto o retorno é positivo, e isso é visto como um investimento, sendo assim esses custos são menosprezados diante dos grandes benefícios do alcance dos resultados, de seu principal objetivo, o lucro (RATKO,2008)

É relevante a importante utilização dessa ferramenta tão visível como a contabilidade no auxílio do processo produtivo, tela forma que fornece informações no auxílio do processo decisório. Leone (2000), dentre as várias aplicações, a contabilidade de custos fornece informações contábeis e financeiras para a decisão entre cursos de ação alternativos onde afirma 
que este tipo de decisão requer informações contábeis que não são facilmente encontradas nos registros da contabilidade financeira. Para obter mais informações é necessário que uma dedicação extra de classificação, combinação e apuração sejam aplicadas para que elas possam ser utilizadas em tais decisões.

A ferramenta competente para selecionar e sistematizar os dados do agricultor com o objetivo de apresentar exatidão seus custos no campo é a Contabilidade. No decorrer das atividades do produtor, pode ocorrer custo inesperado, todavia com um planejamento de custos são bem menores os riscos ao se deparar com o inesperado.

Segundo Leone (2000), a contabilidade de custos pode ser conceituada como o ramo da função financeira que acumula, organiza, analisa e interpreta os custos dos produtos, dos estoques, dos componentes da organização, dos planos operacionais e das atividades de distribuição para determinar o lucro, para controlar as operações e para auxiliar o administrador no processo de tomada de decisões e de planejamento. Ao adotar um sistema de contabilização, esse precisa estar em harmina com a sua estrutura organizacional, seus métodos operacionais e seu tipo de informação de custos que a empresa necessitar obter.

Podemos ver que a contabilidade de custos tem o papel de fornecer a administração de uma empresa com dados que descrevam o total de recursos que foram utilizados para execução do processo administrativo.

Para Callado e Callado (2005), a diversidade de atividades rurais dificulta a apuração dos custos de produção. Isso acontece pela grande dificuldade no controle de elementos em se obter exata apropriação dos custos a cada atividade ou produto.

É essencial que o produtor rural tenha conhecimento sobre a composição e procedimentos dos seus custos para que através dessas informações possa produzir estratégias de execução embasadas de informações confiáveis, na busca de alternativas melhores e possibilitem a visualização antecipada de dificuldades ocorridas nas mudanças de níveis de preço dos elementos integrantes do custo rural. Marion (2012) enfatiza que o sentido gerencial da contabilidade de custos é gradativo no meio rural.

\section{Metodologia}

O estudo foi realizado no Sítio Barra no município de Orós, no Estado do Ceará, junto aos agricultores familiares. O estudo transcorreu entre o período de agosto a outubro de 2018. Participaram da pesquisa apenas os agricultores que se disponibilizaram voluntariamente. Este 
estudo num primeiro momento desenvolveu uma pesquisa bibliográfica, ou seja, um estudo de fontes secundárias sobre a contabilidade rural e suas finalidades, sendo esta primeira fase apresentada no referencial teórico; num segundo momento, foi realizado um estudo de campo, onde os dados foram levantados através de um questionário.

A pesquisa é de natureza básica, com objetivo exploratório, com abordagem quantitativa. Segundo Gil (2010) esse tipo de pesquisa pode ser derivando tanto de constatações e percepções que têm como norte o desenvolvimento esclarecimento ou modificação de conceitos e ideias. A pesquisa objetiva contribuir na demonstração da importância da Contabilidade Rural para o pequeno produtor vista como uma ferramenta que permite, por meio da informação contábil, o planejamento, controle orçamentário para a tomada de decisão.

Para a coleta de dados da pesquisa foi utilizado um questionário estruturado com perguntas objetivas (GIL, 2010), sendo distribuído e aplicado junto a dez (10) produtores rurais do Sítio Barra no município de Orós-CE. A partir das respostas obtidas foi feito uma análise do resultado e demonstrado aos produtores a importância e aplicabilidade da ferramenta contábil, para uma melhor gestão do negócio.

Destaca-se que a pesquisa foi executada conforme os padrões éticos. A partir das orientações da Resolução 466/12 do Conselho Nacional de Saúde, sendo norteado mediante as normas e diretrizes que obedecem aos princípios éticos que garantem a ética em pesquisa.

\section{Análises e Discussões}

A partir da obtenção dos dados buscaram-se analisar a importância e utilização da contabilidade pelos produtores rurais, dados estes que foram apurados do questionário aplicado, que apresentou informações pertinentes à ação dos agricultores e a sua relação com a contabilidade aplicada ao setor rural. A princípio foram elaboradas perguntas que enfatizam a segregação de despesas ligadas ao conhecimento e segregação de despesas ligadas a propriedade, conforme segue o resultado obtido no quadro 1: 


\begin{tabular}{|l|c|c|c|c|c|c|c|c|}
\hline \multicolumn{1}{|c|}{ Questões } & \multicolumn{2}{|c|}{ Nunca } & \multicolumn{2}{c|}{ As vezes } & \multicolumn{2}{c|}{ Sempre } & \multicolumn{2}{|c|}{ Não respondeu } \\
\cline { 2 - 9 } & Fr & Fr (\%) & Fr & Fr (\%) & Fr & Fr (\%) & Fr & Fr (\%) \\
\hline $\begin{array}{l}\text { Você acha que seu } \\
\text { conhecimento sobre gestão } \\
\text { e contabilidade, é o } \\
\text { bastante para controlar sua } \\
\text { propriedade? }\end{array}$ & 7 & 70 & 1 & 10 & 1 & 10 & 1 & 10 \\
\hline $\begin{array}{l}\text { Você separa seus gastos } \\
\text { particulares, como comida, } \\
\text { roupas, contas pessoais, dos } \\
\text { gastos da propriedade } \\
\text { (adubo, sementes)? }\end{array}$ & 3 & 30 & 2 & 20 & 2 & 20 & 3 & 30 \\
\hline $\begin{array}{l}\text { Se conhecesse melhor } \\
\text { como funciona a } \\
\text { contabilidade, a usaria para } \\
\text { auxiliar na gestão de suas } \\
\text { atividades. }\end{array}$ & - & - & 2 & 20 & 7 & 70 & 1 & 10 \\
\hline
\end{tabular}

Quadro 1: Segregação de Despesas

Fonte: Dados da pesquisa (2018).

Os dados do quadro 01 , demonstra que $70 \%$ dos respondentes consideram que seus conhecimentos sobre gestão e contabilidade são insuficientes para fazer o controle da propriedade e das atividades nela realizadas.

Ainda é possível evidenciar, que a maior parte dos agricultores participantes confirma não fazer a separação dos gastos pessoais com gastos das atividades por eles realizadas nas propriedades, segundo postula o princípio da entidade contábil, enfatizando que apenas $20 \%$ declaram realizar esse tipo de controle.

Em se tratando de um melhor conhecimento sobre a contabilidade aplicada ao setor rural foi perguntado se funcionaria melhor sua atividade tendo tal conhecimento, $70 \%$ confirmou que se houvesse uma maior informação sobre a funcionalidade da contabilidade no auxílio das atividades do meio rural se faria a utilização dessas no processo de orientação e também de gestão das propriedades, vindo assim demonstrar uma perspectiva de crescimento e aplicação da contabilidade no espaço rural. 
Quadro 2: Entendimento sobre lucro das despesas

\begin{tabular}{|c|c|c|c|c|c|c|c|c|}
\hline \multicolumn{9}{|c|}{ Parâmetros fr(\%) } \\
\hline \multirow[t]{2}{*}{ Questões } & \multicolumn{2}{|c|}{ Nunca } & \multicolumn{2}{|c|}{ As vezes } & \multicolumn{2}{|c|}{ Sempre } & \multicolumn{2}{|c|}{$\begin{array}{c}\text { Não } \\
\text { respondeu }\end{array}$} \\
\hline & $\mathbf{F r}$ & $\operatorname{Fr}(\%)$ & $\mathbf{F r}$ & $\operatorname{Fr}(\%)$ & $\mathbf{F r}$ & $\operatorname{Fr}(\%)$ & $\mathbf{F r}$ & $\operatorname{Fr}(\%)$ \\
\hline $\begin{array}{l}\text { Caso utilize a contabilidade, ela } \\
\text { é realizada também para o } \\
\text { gerenciar o negócio e na } \\
\text { tomada de decisões? }\end{array}$ & 7 & 70 & 1 & 10 & 1 & 10 & 1 & 10 \\
\hline $\begin{array}{l}\text { Você sabe qual o lucro da } \\
\text { propriedade, controlando } \\
\text { quanto entra e quanto sai de } \\
\text { dinheiro? }\end{array}$ & 2 & 20 & 3 & 30 & 5 & 50 & - & - \\
\hline $\begin{array}{l}\text { Você reinveste seu lucro na } \\
\text { propriedade, comprando } \\
\text { máquinas ou melhorando o } \\
\text { processo produtivo? }\end{array}$ & 2 & 20 & 8 & 80 & - & - & - & - \\
\hline
\end{tabular}

Fonte: Dados da pesquisa (2018).

Percebe-se no quadro 02, que 50\% dos agricultores possuem o controle das entradas e saídas, bem como da lucratividade obtida em suas propriedades. É relevante o dado, onde mostra que $80 \%$ dos produtores, não reinvestem parte do que ganham em maquinário ou na melhoria do processo produtivo, pois reinvestir, ou fazer melhorias na propriedade ou atividade rural é importante para o crescimento da mesma.

Sabendo que o lucro é a força que impulsiona a atividade financeira, o não acompanhamento dificulta a definição de objetivos e a análise de execução no decorrer das atividades.

Quadro 3: Uso de controle e interesse por orientação.

\begin{tabular}{|l|l|l|l|l|l|l|l|l|}
\hline \multicolumn{7}{|c|}{ Parâmetros fr(\%) } \\
\hline Questão & \multicolumn{2}{|c|}{ Nunca } & \multicolumn{2}{|c|}{ As vezes } & \multicolumn{2}{c|}{ Sempre } & \multicolumn{2}{c|}{ Não respondeu } \\
\hline & Fr & Fr (\%) & Fr & Fr (\%) & Fr & $\begin{array}{l}\text { Fr } \\
(\%)\end{array}$ & Fr & $\begin{array}{l}\text { Fr } \\
(\%)\end{array}$ \\
\hline $\begin{array}{l}\text { Caso utilize a contabilidade, } \\
\text { ela é realizada também para o } \\
\text { gerenciar o negócio e na } \\
\text { tomada de decisões? }\end{array}$ & 7 & 70 & 1 & 10 & 1 & 10 & 1 & 10 \\
\hline $\begin{array}{l}\text { Você sabe qual o lucro da } \\
\text { propriedade, controlando } \\
\text { quanto entra e quanto sai de } \\
\text { dinheiro? }\end{array}$ & 2 & 20 & 3 & 30 & 5 & 50 & - & \\
\hline $\begin{array}{l}\text { Você reinveste seu lucro na } \\
\text { propriedade, comprando } \\
\text { máquinas ou melhorando o } \\
\text { processo produtivo? }\end{array}$ & 2 & 20 & 8 & 80 & - & - & - & \\
\hline
\end{tabular}

Fonte: Dados da pesquisa (2018). 
O quadro 03 demonstra a ausência de uso da contabilidade, visto que 80\%, não utilizam qualquer espécie de controle para a escrituração dos custos, atividades de manutenção da propriedade. Já dez por cento asseguram fazer anotações simples de controle das tarefas realizadas, outros $10 \%$ revelaram fazer algum tipo de controle de gastos e despesas e entrada de dinheiro em planilhas eletrônicas. Em relação a acreditar que a contabilidade pode ajudar no controle de despesa, custo e lucratividade, $60 \%$ evidenciaram esse pensamento.

\section{Considerações Finais}

Conclui-se que os princípios estudados e dados coletados dos agricultores entrevistados, não utilizam a contabilidade de nenhuma forma em suas atividades rurais. Conforme os entrevistados, a admissão de uma colaboração contábil representa mais como um gasto do que como um resultado positivo em suas atividades. Essa condição acontece devido a vários aspectos, como exemplo a falta de conhecimento do produtor em relação aos benefícios da contabilidade para sua atividade, e também o desinteresse de contadores em procurar trabalhar com esse tipo de atividades, principalmente os pequenos produtores rurais.

Os resultados obtidos nos 09 quesitos aplicados possibilitam perceber que a mão-deobra é basicamente familiar sem inserção de terceiros. Bem como também confirmaram não separar os gastos pessoais dos gastos utilizados na atividade rural.

A partir da análise dos resultados foi percebido o interesse por conhecimentos e esclarecimentos sobre contabilidade e no que essa possa acrescentar na melhoria das atividades dos agricultores. Perante o que foi exposto, constatou-se que a contabilidade rural embora já bem avançada em vários setores do agronegócio ainda é um campo a ser investigado e percorrido, pois a aplicação contábil não é apenas demostrar dados ao fisco, mas vem subsidiar as dificuldades dos gestores em tomadas de decisões.

Contudo com o intuito de que ocorra uma maior utilização de serviços contábeis por produtores rurais de pequeno porte é notório que se desenvolva o costume, ou hábito da aplicação de informações contábeis, no processo diário dos produtores em suas atividades rurais. No entanto é importante destacar que para que possa ocorrer uma maior procura por este serviço, os profissionais contábeis, precisam difundir a importância do instrumento contábil para procedimentos utilizados em atividades rurais sejam eles de pequeno ou grande porte, com 
poucos ou muitos agricultores que participem de associações ou mesmo aqueles que se organizam em suas comunidades.

\section{Referências}

AURÉLIO, B. H. Dicionário da língua portuguesa. 5. ed. Curitiba: Positivo, 2010.

CALDERELLI, A. Enciclopédia Contábil e Comercial Brasileira. 28 ed. São Paulo: CETEC, 2003.

CALLADO, A. A. C; CALLADO, A. L. Gestão de custos para empresas rurais. 2005. Disponível em: <http://bis.sebrae.com.br/GestorRepositorio.pdf > Acesso em: 30 set. 2018.

CALlADO, A. A. C. Agronegócio. São Paulo: Atlas, 2011.

CHAGAS, M. F. et al. O USO DA CONTABILIDADE COMO INSTRUMENTO DE CONTROLE NA ATIVIDADE RURAL. Diálogos em Contabilidade: Teoria e Prática, v. 2, n.1, 2014.

CREPALDI, S. A. Contabilidade Rural: Uma abordagem decisorial. 3. Ed.São Paulo: Atlas, 2005.

CREPALDI, S. A. Contabilidade Rural: Uma abordagem decisorial. 7. ed. São Paulo: Atlas, 2012.

GIL, A. C. Como Elaborar Projetos de Pesquisa. 5. ed. São Paulo: Atlas, 2010.

GOMES, A. R. Contabilidade Rural e agricultura familiar. Rondonópolis: A.R. Gomes, 2002.

BORILLI, S. P. et al. O USO DA CONTABILIDADE RURAL COMO UMA FERRAMENTA GERENCIAL: UM ESTUDO DE CASO DOS PRODUTORES RURAIS NO MUNICÍPIO DE TOLEDO - PR. Rev. Ciên. Empresariais da UNIPAR, v.6, n.1, 2005.

LEONE, G. S. G. Curso de Contabilidade de Custos. São Pulo: Atlas, 2000.

MARION, J. C. Contabilidade Rural: Contabilidade Agrícola, Contabilidade da Pecuária, Imposto de Renda - Pessoa Jurídica. 7. ed. São Paulo: Atlas, 2012.

RATKO, A.T. Contribuições da contabilidade rural para propriedade agrícola de pequeno porte. Trabalho de Conclusão de Curso (Monografia de Ciências Contábeis) - Universidade Tecnológica Federal do Paraná - UTFPR, Pato Branco, 2008.

Como citar este artigo (Formato ABNT):

DIAS, Eliza Costa; ANDRADE, Marzo Tereshkove Anacleto e; GOMES FILHO, Antoniel dos Santos. Contabilidade Rural: Um Estudo com Pequenos Produtores Rurais do Sítio Barra no Munícipio de Orós, Ceará-Brasil. Id on Line Rev.Mult. Psic., 2019, vol.13, n.43, p. 164-174. ISSN: 1981-1179. 